EDITORIAL

\title{
Science Gender Gap: Are We in theRight Path?
}

\author{
Gláucia Maria Moraes de Oliveira, ${ }^{1 \bullet}$ Marge Tenorio, $^{2}{ }^{\circledR}$ Alessandra de Sá Earp Siqueira $^{2}$ \\ Universidade Federal do Rio de Janeiro,' Rio de Janeiro, RJ - Brazil \\ Departamento de Ciência e Tecnologia da Secretaria de Ciência, Tecnologia e Insumos Estratégicos do Ministério da Saúde (Decit/SCTIE/MS), 2 \\ Brasilia, DF-Brazil
}

Women are entering the medical and scientific community in growing numbers, reaching and even surpassing their male counterparts in medical schools. However, a settled imbalance between men and women is still a reality in the international cardiology community despite these recent advances. ${ }^{1}$ The female presence in Brazilian medical schools was barely noticed until the 1960s; in the following years, there was a gradual increase in the number of women in the medical field, mainly in the first decade of the 21st century (59\% in 2020). In a 2020 demographic analysis of the Brazilian Federal Council of Medicine, men still predominated, accounting for 53.4\% of all doctors in the country. Nevertheless, in the age-range below 30-years-old, women are the majority, accounting for $58.5 \%$; the percentage of female doctors is inversely proportional to the increase in the age group, with only $21 \%$ of women in the age group above 70 years old. ${ }^{2}$

In the USA, women represent less than $15 \%$ of the cardiology workforce and less than $5 \%$ of interventional cardiologists, ${ }^{2}$ while in Europe, women account for only one-third of cardiologists, and 18\% of women are interventionists. ${ }^{3}$ Currently, Brazil has nearly 500 thousand doctors, 17,802 thousand cardiologists, of which $31.1 \%$ are females, and mostly concentrated in the southeast region. In 2018, only 215 (8.6\%) of a total of 2,062 cardiovascular surgeons and $7.5 \%$ of 970 interventional cardiologists were women. ${ }^{4}$ The Brazilian Society of Cardiology had two female presidents; and the Cardiovascular Surgery Society, the Interventional Cardiology, and the Federation of Portuguese Language Cardiology Societies had one female president. Also, in the last five years, only one fifth

\section{Keywords}

Cardiovascular Disease; Cardiologists; Women; Ethics; Gender Identity; COVID-19; Pandemic of the speakers in the annual congress of the Brazilian Cardiology Society were women.

There are more male than female doctors in the private sector $(23.9 \%$ vs. $14 \%)$, and more women in the public and academic sectors ( $53 \%$ vs. $44 \%$ of men). Among the professionals who work 20 and 40 hours a week, only $2.7 \%$ of the women earn US\$10,762 per month compared to $13 \%$ of men. The likelihood of male doctors earning more than US $\$ 10,762$ is $17 \%$, and of female doctors, only $4 \%$. Wage inequality between genders persist concerning workload, and office and on-call hours. ${ }^{2}$ In the USA, white women earn 77 cents on the dollar, black women, 79 cents, and Asian women 75 cents comparing with male physicians in their own racial or ethnic groups. Although these data come from academic medical institutions only, they reflect the compensation of 60,000 physicians. ${ }^{5}$ In an era when half of the medical students are women, these professionals will not succeed unless institutions make a commitment to improve processes and reshape practices and patterns at workplace that have been inadvertently benefited men and detrimental to women; additionally, these practices have upheld the unjustified and deeply troubling gender pay gap. ${ }^{6}$

Gender gap in science and academic careers is not new. According to US data, less than 30\% of the world's researchers are women. Also, high-status awards and positions are less likely to be given to women in science. ${ }^{7}$ A Brazilian study ${ }^{8}$ found that female scientists who hold a productivity scholarship and obtain more funding are at the lower levels of the research ranking system. In addition, only $14 \%$ of the Brazilian Academy of Science members were women. ${ }^{8}$ The authors pointed out several factors that contribute to the underrepresentation of women in higher positions and leadership. However, the primary factor influencing women's career in science is still an understudied topic: motherhood. ${ }^{8}$ 
Another study analyzed the influence of gender, parenthood, and race on academic productivity during the pandemic period based on a survey responded by 3,345 Brazilian academics from various knowledge areas and research institutions. The authors found that male academics, especially those without children, were the least affected group. In contrast, Black women and mothers were the most impacted groups because of the uneven domestic division of labor between men and women, exacerbated during the pandemic. ${ }^{9}$

Results from the latest Organization for Economic Cooperation and Development (OECD) International Survey of Scientific Authors (ISSA2) showed that women are underrepresented in research careers. On average, across OECD countries, only nearly $40 \%$ of all the investigators are women - ranging from $23 \%$ in Luxembourg to $56 \%$ in Lithuania - and they are considerably less likely to be in leadership positions. Only $30 \%$ of corresponding authors are women. Also, women authors earn on average 5 to $6 \%$ less than their male counterparts, even after accounting for individual and job-related characteristics. ${ }^{10}$

In addition to productivity grants, we can also analyze the Gender Gap in Science through the research supported by the Department of Science and Technology (DECIT) of the Secretariat of Science and Technology and Strategic
Inputs (SCTIE) of the Brazilian Ministry of Health, currently under the leadership of a woman. Figure 1 shows the distribution DECIT/SCTIE/HM-funded research projects from 2010 to 2021 by sex and federative units. There are significantly more projects coordinated by women, mainly in the states of Rio Grande do Sul (RS), Minas Gerais MG), and Bahia (BA). The number of projects coordinated by men was higher in the states of Piaui (PI), Rio Grande do Norte (RN), Roraima (RR) and São Paulo (SP).

In Figure 2, we can see the distribution of research funding from the DECIT/SCTIE/MS by sex and geographic region from 2010 to 2021. In this period, the average funding for the total number of studies was $R \$ 248$ thousand, except in the southeast region (average of $\mathrm{R} \$$ 472 thousand). All other regions were below the national average. Interestingly but unfortunately, the average value per project coordinated by men was higher than those coordinated by women, which was even more evident in the north and south regions of the country, where the average funding per project coordinated by men was twice the value observed for women.

Figure 3 shows the distribution of the proportion of resources invested, by sex, in the 20 most-funded areas of research according to the National Agenda of Health Research Priorities of the Brazilian Ministry of Health

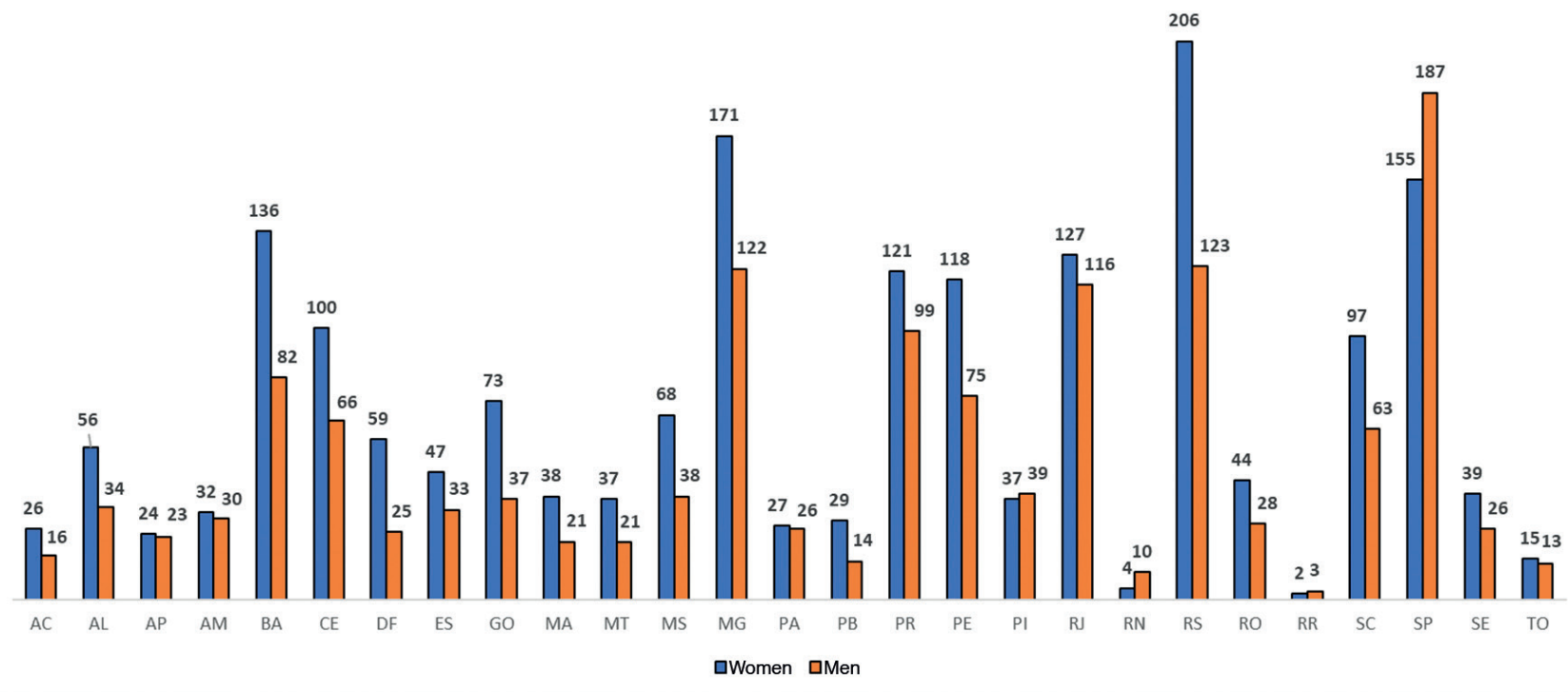

Figure 1 - Distribution of research projects funded by the Department of Science and Technology (DECIT) of the Secretariat of Science and Technology and Strategic Inputs (SCTIE) of the Brazilian Ministry of Health from 2010 to 2021 by sex and federative units of Brazil.

Source: Management database of the Department of Science and Technology (DECIT) of the Secretariat of Science and Technology and Strategic Inputs (SCTIE) of the Brazilian Ministry of Health. 

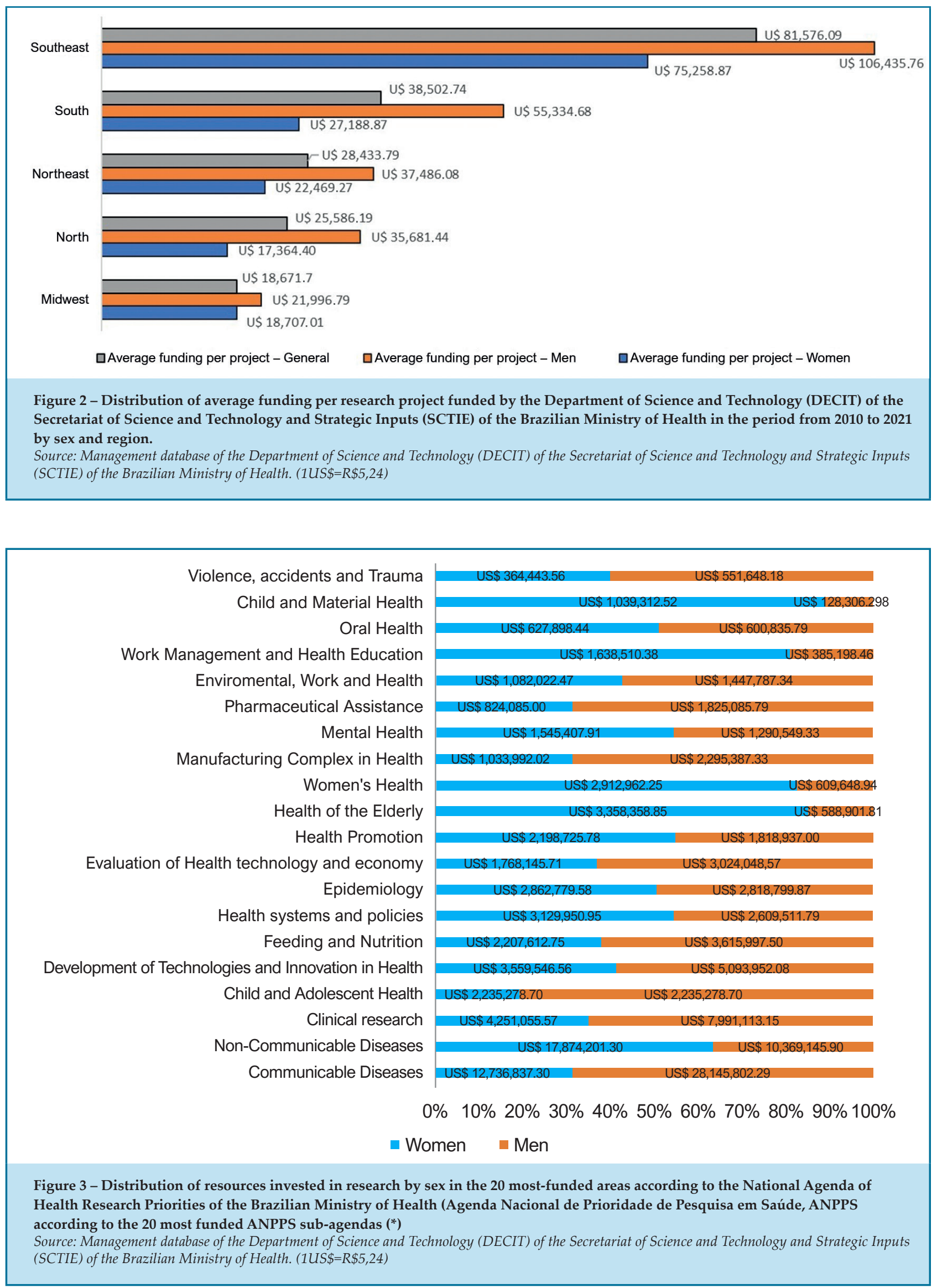
(Agenda Nacional de Prioridade de Pesquisa em Saúde, ANPPS). Again, a gender gap is observed. Also, it is noticed that the themes "Maternal and Child Health", "Work Management and Health Education", "Women's Health", and "Health of the Elderly" concentrate more than $70 \%$ of the resources invested in research coordinated by women.

In addition, a summary of research projects funded by the DECIT (Table 1) shows that the gap persists, since although female researchers hold more contracts, they are granted less funding. The comprehensive depiction of gender inequality in health sciences may provoke a discussion about the sustainability of women's careers, and provide a basis for decision-makers of health policies. ${ }^{11}$ The equitable presence of women in advisory and administrative bodies of health favors the formation of an environment based on societal and democratic principles. ${ }^{12}$

To change the inequality setting, we have to invest in public policies to identify the flaws and rearrange the relations to value the differences, and make it sustainable and inclusive, in a way that female researchers could reconcile family, private and professional life. Optimization of women's participation in research projects goes through more investment. Our compelling task is to create a more favorable institutional and healthier environment for women and men, without losing the bigger picture of potentially introducing fundamental changes in the Brazilian society.

Table 1 - Number of research contracts in force and total amount of funds invested by the Department of Science and Technology (DECIT) of the Secretariat of Science and Technology and Strategic Inputs (SCTIE) of the Brazilian Ministry of Health for male and female researchers from 2010 to 2021

\begin{tabular}{|c|c|c|c|c|c|}
\hline & WOMEN & $\%$ & MEN & $\%$ & Total \\
\hline Contracts inforce & 1,888 & 57.95 & 1,370 & 42.05 & 3,258 \\
\hline Funds invested & US\$ $68,642,246.21$ & 44.42 & US\$ $85,896,666.52$ & 55.58 & US\$ $154,538,912.73$ \\
\hline
\end{tabular}

\section{References}

1. Borrelli N, Brida M, Cader A, Sabatino J, Czerwińska-Jelonkiewicz K, Shchendrygina A, on behalf of the Pink International Young Academy of Cardiology, Women leaders in Cardiology. Contemporary profile of the WHO European region, Eur Heart J Open.2021;1(1):oeab008 https:// doi.org/10.1093/ehjopen/oeab008

2. Scheffer M, Cassenote A, Guerra A, Guilloux AA; Brandão AP, Miotto B, et al. Demografia Médica no Brasil 2020. São Paulo(SP):FMUSP/ CFM;2020.312p. ISBN: 978-65-00-12370-8.

3. Burgess S, Shaw E, Zaman S. Women in cardiology. Circulation.2019;139(8):1001-2. https://doi.org/10.1161/ CIRCULATIONAHA.118.037835

4. Sinclair HC, Joshi A, Allen C, Joseph J, Sohaib SMA, Calver A, Smith R. Women in cardiology: The British Junior Cardiologists' Association identifies challenges. Eur Heart J. 2019;40(3):227-31. Doi;10.1093/ eurheart/ehy 828

5. Dandar VM, Lautenberger DM, Garrison G. Exploring faculty salary equity at U.S. medical schools by gender and race/ethnicity. Washington, DC: Association of American Medical Colleges, October 2021. Doi: (https://www.aamc.org/data-reports/workforce/report/ exploringfaculty-salary-equity-us-medical-schools-gender-and race/ethnicity)

6. Gottlieb AS,Jagsi R. Closing the Gender Pay Gap in Medicine. N Engl J Med. 2021; 385(27):2501-4. DOI: 10.1056/NEJMp2114955
7. Lunnemann P,Jensen L, Mogens H, Jauffred L. Gender bias in nobel prizes. Palgrave Commun.2019;5(1):e4000. Doi: 10.1057/s41599-0190256-3

8. Valentova JV, Otta E, Silva ML, McElligott AG. 2017.Underrepresentation of women in the senior levels of Brazilian Science. PeerJ 5: e4000 https:// doi.org/10.7717/peerj.4000

9. Staniscuaski F, Kmetzsch L, Soletti R C, Reichert F, Zandonà, E. Gender, race and parenthood impact academic productivity during the COVID-19 pandemic: from survey to action. Front Psychol.2021;12:663252. Doi. org/10.3389/fpsyg.2021.663252

10. Bello M, Galindo-Rueda F. "Charting the digital transformation of science: Findings from the 2018 OECD International Survey of Scientific Authors (ISSA2)", OECD Science, Technology and Industry Working Papers, No. 2020/03 Paris;2020. https://doi.org/10.1787/1b06c47c-en

11. Huanga,J, Gatesa AJ, Sinatrad R, Barabasi AL- Historical comparison of gender inequality in scientific careers across countries and disciplines. Proceedings of the National Academy of Sciences . Proc Natl Acad Sci USA.2020;117(9):4609-16. DOI: 10.1073/pnas.1914221117

12. Mehran R, Vogel B. Women and cardiac disease: a special issue. Int J Cardiovasc Sci. 2021; 34(4):338-9. DOI: https://doi.org/10.36660/ ijcs.20210173 